\title{
Research Optimization for the Utilization-Exploitation of Hellenic Army Vacant Warehouses
}

\author{
Theodoros Zikos ${ }^{1 *}$, Dimitrios Zaires ${ }^{2}$, and Nikolaos V. Karadimas ${ }^{3}$ \\ ${ }^{1}$ Colonel, Hellenic Army General Staff, Thessalonica, Greece \\ ${ }^{2}$ S.Lieutenant, Hellenic Army General Staff, Orestiada, Greece \\ ${ }^{3}$ Lecturer of Informatics, Hellenic Army Academy, Mathematics and Engineering Sciences, Vari, Greece
}

\begin{abstract}
The aim of this paper is the research optimization of all factors concerning the utilization and exploitation of empty warehouses belonging to the Hellenic Army, pointing out that in periods of economic crisis the Hellenic Army has the capability of self-sustainability at every level of command. This approach analyzes the acknowledge of the objectives and the strategies employed by the Hellenic Army Logistics Department and also the analysis of the environment (internal and external), approaching factors that lead to the necessity of the exploitation, such as the adequacy of the warehouses, the reduction of human resources, the difficulty of maintaining the facilities by allocated credits and the capability of their evacuation. Formal methods like SWOT (Strengths, Weaknesses, Opportunities, Threats) analysis, Political/Law, Economic, Social, Technological, Demographic, Global Environment analysis, structural-industry analysis of the competitive environment and value chain analysis are used for the accurate determination of all optimal options which will lead to the best possible solution for the development and utilization of the aforementioned facilities. This optimization which invests in the extroversion of the Hellenic Army enhances our vision for the full utilization - operation of the Hellenic Army Empty Warehouses.
\end{abstract}

\section{Introduction}

This paper is to analyse all factors concerning the utilization and exploitation of empty warehouses belonging to the Hellenic Army pointing out that in periods of economic crisis the Hellenic Army has the capability of self-sustainability at every command level and propose all optimal solutions for the their fully operation. In this context for research optimization and the assessment of all factors followed the strategic management process [1], so that these solutions are functional at all levels of command of the Hellenic Army (Departmentorate - business - functional levels).

\section{PEST-DG Analysis}

The Political/Law, Economic, Social, Technological, Demographic, Global Environment (PEST-DG) analysis [2] contributed with four ways to "strategic analysis" for the utilization - operation of Hellenic Army empty warehouses:

1. The factors recorded, are not only a source of information, but could also serve as model variables that will help identify the most important influences of the external environment.

2. It leads the Logistics Department in selecting a minimum number of key factors affecting it and its competitors, hence its strategic location.
3. Used to identify "long-term drivers of new changes".

4. Leads to examine the factors that historically and prospectively affect a business and the industry in which it operates (impact analysis).

In particular, the economic crisis and the existing financial situation of the country does not permit for the next few years the appropriation of the necessary credits for maintaining the existing facilities, the construction of new ones, the obtainment of new arms systems and the creation of stock while the existing one keeps decreasing.

Another very significant factor which affects the maintenance of the facilities prevailing throughout the year is weather conditions. Strong winds which most of the times destroy (lift) the roofs, heavy rainfall and snowfalls during the winter destroy the clear plastic and the gutters creating static issues for the buildings. Other factors that the PEST-DG analysis emerge positive and negatives are:

- finding of financial resources,

- the exploitation of inactive facilities,

- incentives for providing more logistics services,

- exploitation of the National Strategic Reference Framework (NSRF) programs,

- lack of experience of relevant collaboration of the Unit with individuals,

- the ensuring deterrence of storing illegal products (smuggled etc.) due to the frequent controls by

\footnotetext{
Corresponding author: hellas.ted@gmail.com
} 
the competent services within the military facilities if they are rented to individuals.

\section{Structural-Industry Analysis of the Competitive Environment}

According to the model of the five forces of Porter [3] or model of structural analysis of an industry the five forces that determine competition are:

1) The intensity of competition between existing firms in the industry. This analysis should lead to the recovery of those factors that should focus the interest of the Hellenic Military Logistics Department.

2) The new companies entering the industry: The new entry threat in existing markets increases as decreasing the "entry barriers") such us, the amount and cost of capital required, access to distribution channels, cost advantages regardless of size, expected retaliation, National laws or government intervention.

3) Bargaining Power Suppliers: The power of suppliers increases when there is centralization of suppliers, the "replacement cost" of a supplier to another is very high, is highly likely that "vertical integration forward" on the part of the supplier, customers of a supplier are not important, and the supplier is not looking forward to a long-term cooperation with them.

4) Bargaining Power of Buyers: When there is a centralization of all buyers, or where the quantities purchased are great, when there are alternative sources of supply (undifferentiated product) and there are many companies that produce many products.

5) The Threat of Substitute Products. This risk has three forms:

a) a real risk of similar replacement product.

b) a new production process can put aside the use of a product.

c) certain products may compete completely different.

As each company, so the Hellenic Military Logistics Department has to responds to the following questions: "Replacement products (Empty Warehouses) render inoperable our products or just give the impression to the consumer of greater benefits or higher value?", "How easy is it for the consumer replacement decision?", "What is that cost?", "How the replacement risk can be reduced?" In this context, the Hellenic Army has the capability as an alternative optimal choice to offer the vacant warehouses for rent to individual companies.

So, the Hellenic Army after the identification of the main factors in the external environment and the assessment of the competitors in relation to whether the main factors influencing their own place (in the past, present and future) reached the following conclusions: Collaboration with logistics companies (3PL and 4PL), which in many cases may see the move of the Unit as competitive.

\section{Value Chain Analysis}

In this phase, an indicative value chain is analysed [4], started with the Resource-Capabilities Audit and emerge the logistics work context of the Hellenic Army Logistics Department such us the existing experience in material management, the storage evacuation capability etc.

\subsection{The Main Functions}

According to international Logistics standards [5], [6], which the Army follows, a supply unit can perform the following tasks:

- Receive, store and preserve/maintain the materials from the supply internal and external sources,

- Supply the operational units with materiel,

- Receive and handle the returnable materiel by the operational units by separating the inspected one from the useless one and forward it for recyclerepair etc.,

- Complies materiel stocks with statutory orders of superior squads and relevant plans,

- Make regular and occasional stocktaking so that there will be at any moment absolute accordance between the audit and the physical inventory,

- Cover the operational needs - the Logistics.

Additionally, the common ways to secure a military base [7] where the units and their facilities are located can be achieved with garrison and security departments, military dogs and their companions, system of circumferential visual surveillance, alarm systems in the warehouses, perimeter wall and barbed wire. In this context, main factors involved in storage [5] are the flow of spare parts - materials from the supply sources, the existing management of the materials, the existing facilities (warehouses) and the warehouse equipment. In the case of warehouse equipment, in packaging materials are crates palettes, etc., in storage materials are shelves, tubs, chests of drawers, etc., in materials for warehouses protection are insulations, water leaks, etc. and finally are the storage conditions, as well.

\subsection{Operations - Management of Materials}

The placement of the materials in the warehouses of a single management takes place according to the class of the material. The class of every material concerns the general category to which the material belongs. For example, a class of material is generally pneumatic tires - air chambers or engines. A similar procedure was followed for grouping all the materials in order to be placed in the warehouses of every management. The level of the stock in the departments is substantially low. Furthermore, it is estimated that in the near future this situation will not change, on the contrary, it is estimated that due to the financial situation of the country the level of the stock will be diminished. 


\subsection{Existing Facilities}

The existing facilities, where other military units or even public or private companies such as individual logistics companies could storage their materials, are located in the main distribution centers next to major transport hubs, airports and ports. They are composed by:

- Administrative areas, which houses transaction and administrative support offices.

- Storage rooms, where management of materials is located and include the warehouses.

- Storage sheds, where bulky materials are stored in layers.

- Back-up facilities, such as export center, squads for receiving foreign materials - trade etc.

\subsection{Storage Optimization Capability}

Through the optimization of the warehouses the following is succeeded:

1. Better monitoring of the materials since the multiple positions for every material are limited.

2. Reduction of movement of personnel and means.

3. More effective maintenance of the materials.

4. Better maintenance of the warehouses, which contain materials only, whereas, those which do not contain materials are led to obsolescence due to the almost minimal appropriated credits.

Under these conditions, a gradual transfer of the materials of every management has taken place by concurrent arrangement of the materials at the new warehouse and at the same time actions were initiated for the transfer of the next materials in order to avoid any problems. The transfer of the materials of the management takes place after a full inventory of the materials which can be moved and placed in secure places appropriate for storing the corresponding materials.

\subsection{Secondary Functions}

Human Resources: The existing staff of the units is expected for the military personnel to be maintained or reduced according to the transfers-assignments of the executives. For the civilian personnel is expected to be reduced due to retirements and the suspension of recruitments mainly of technical staff and workers.

The Engineering Department of the Army has the knowledge and the expertise to cover the requirements for the maintenance of the facilities but due to financial situation of the country and the big number of the existing bases makes this not possible today. Simultaneously, they are not permitted the appropriation of the necessary credits for the procedure of the maintenance.

These factors combined with the adequacy of the warehouses and the capability of their evacuation reinforcing the need of finding alternative resources for their maintenance and their fully exploitation and employment.

\section{Recourse Validation - Utilization of Vacant Warehouses}

Therefore, it is understandable that the creation of competitive advantage depends on how each company manages the "value system" [4]. Labelling of operations contributing to creating and sustaining competitive advantage, which can be either reduced cost with stable prices thus increasing profit margins than the competition or product differentiation by achieving higher prices than the competition and therefore higher margin.

1. Analysing the Cost Efficiency: Cost efficiency is important for companies competing in the basis of continuous decline of the cost of their products.

2. Analysing the Cost Effectiveness: Effectiveness is the most important instrument of business competing by differentiating their products. The assessment of effectiveness is related to how well a company adapts its products to the existing needs of consumers. This assessment should be done only in those activities of the "competitive strategy" (competitive business level strategy), and aims at finding the "cost drivers or value" of each action.

This means that Hellenic Army's vacant warehouses can be exploited by individual logistics companies, by other military units or by the personnel of the Armed Forces by paying a fee. This leads us to the utilization of the vacant warehouses. For this purpose, a research was conducted at the local logistics companies in order to collect information about the modern methods they apply to the maintenance, as well as to receive suggestions regarding their use.

The investigation showed that the companies maintain their facilities from the income they make via the storage of materials-products. It is indicative that a warehouse with dimensions of $500 \mathrm{~m} 2$ similar to the one in the Hellenic Army Unit's is rented for the amount of 2.500 euros on a monthly basis. Additionally, the logistics companies face a serious problem with their safety and thus they spend a lot of money on security. However, the most important is that they showed an interest at the prospect of renting warehouses from the Army to individuals.

\section{SWOT Analysis}

It is considered imperative before proposing the necessary optimal actions to be taken for the exploitation of the warehouses, to define within the unit the strong and weak points as well as to distinguish the opportunities given at the exterior space as well as the threats that may emerge. This traditional study is known as Strengths, Weaknesses, Opportunities, Threats (SWOT) analysis and is the environment, which has already preceded by assessing each element separately. 
Table 1. The SWOT analysis table.

\begin{tabular}{|c|c|c|}
\hline & Positive Factors & Negative Factors \\
\hline 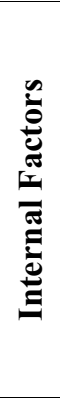 & $\begin{array}{l}\text { - Strengths } \\
\text { - Adequacy of the storage } \\
\text { rooms. } \\
\text { - Safety of the military } \\
\text { facilities. } \\
\text { - The personnel are trained } \\
\text { - Geographical position of } \\
\text { the Unit } \\
\text { - Fully organized and } \\
\text { operational logistics } \\
\text { system. }\end{array}$ & $\begin{array}{l}\text { Weaknesses } \\
\text { - Staff reduction of the Unit. } \\
\text { - Problems of maintaining } \\
\text { the existing facilities. } \\
\text { - Bureaucratic approval } \\
\text { procedures to use military } \\
\text { facilities by individuals. }\end{array}$ \\
\hline 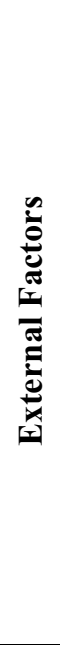 & $\begin{array}{l}\text { Opportunities } \\
\text { - Finding financial } \\
\text { resources. } \\
\text { - Exploitation of inactive } \\
\text { facilities. } \\
\text { - Reconstruction of the } \\
\text { spirit 'management; to } \\
\text { the personnel of the Unit. } \\
\text { - Extroversion. } \\
\text { - Incentives for providing } \\
\text { more logistics services. } \\
\text { - Collaboration with } \\
\text { logistics companies (3PL } \\
\text { and 4PL). } \\
\text { - Exploitation of the NSRF } \\
\text { programmes. }\end{array}$ & $\begin{array}{l}\text { Threats } \\
\text { - Individuals' entry to } \\
\text { military facilities with } \\
\text { what this might mean for } \\
\text { security issues for the } \\
\text { camp. } \\
\text { - Lack of experience of } \\
\text { relevant collaboration of } \\
\text { the Unit with individuals. } \\
\text { - Ensuring deterrence of } \\
\text { storing illegal products } \\
\text { (smuggled etc.) due to the } \\
\text { frequent controls by the } \\
\text { competent services within } \\
\text { the military facilities. } \\
\text { - Logistics companies (3PL } \\
\text { and 4PL) to see the move } \\
\text { of the Unit as competitive. }\end{array}$ \\
\hline
\end{tabular}

A major advantage of the unit and the main source of its power is the big number of storage rooms. The existence of warehouses of different dimensions and construction gives the opportunity for storing different kinds of materials as well as better grouping of the materials. The management of the materials is conducted through logistical equipment which helps all the operations of the Unit. Finally, it can provide multifaceted safety not only in safeguarding the material which is in the storage rooms but also protecting from external threats.

A great weakness is considered to be the lack of cash flow for the maintenance of the facilities and the bureaucratic approval procedures to be used military facilities by individuals.

The economic crisis constitutes a very big opportunity for concluding trade agreement regarding the exploitation of the empty warehouses since individuals, companies and agencies (of the public and private sector) are looking for inexpensive storage rooms. Under these circumstances a unit should invest in extroversion.

The threats emerging from the exploitation of the empty warehouses are the entry of unknown personnel to the unit if they are given for rental as well as the monitor of the materials which will be stored in order to ensure deterrence of illegal materials (smuggled, forbidden, etc.). Finally, the logistics companies (3PL and 4PL) will react negatively when they see the Unit as a competitor which claims a share in the market.

\section{Optimization Proposal}

The strategic management process for the utilization operation of the Hellenic Army Empty Warehouses leads us to format strategies, implement them and evaluate the results. The evaluation of "basic skills" and the "distinctive competencies" of the enterprise is required in order to understand the "strategic skills". As a result of this procedure, is attempted the approach of all optimal solutions for the fully utilization and exploitation of the Hellenic Army Empty Warehouses. These are:

1. Logistics Companies: They showed an interest at the prospect of renting warehouses from the Army

2. Conferral of the warehouses to other Units: No necessity and face problems of concerning their structure, monitoring and use, maintenance due to lack of funding.

3. Used by the personnel of the Armed Forces by paying a fee: There was an interest in using these warehouses by the personnel of the Armed Forces by paying a fee (Not fully exploited).

The exploitation of the warehouses by the Hellenic Army units suggests also the best possible provision of information for their operational use. Our competitive advantage is the extroversion [8] of Hellenic Army, the lower cost we provide, our fully organized and operational logistics system, the social acceptance, our ethical Departmentorate responsibility and devotion to duty.

\section{CONCLUSION}

This paper consists a research optimization for the exploitation of the Hellenic Army Empty Warehouses, aiming to achieve optimal solutions by analysing the strategic level of the logistics Department. In addition, identifies all optimal alternative options for the decision analysis procedure [9] created with a view to take the full advantage - exploitation of the existing vacant warehouses.

Research in Utilization - Exploitation of the Empty Warehouses of the Hellenic Army until now limited and can be furthered to combine aspects such as multiplecriteria decision analysis with the use of the Analytic Hierarchy Process (AHP), which is a structured technique for organizing and analysing complex decisions in the functional level.

Moreover, the literature is lacking when it comes to objectives other than optimization and decision making of the vacant military facilities. In this context, the area that will garner attention for the use of the Military Warehouses from individual logistics companies is the Project Management. Network Analysis (Activity On Node, Activity on Arrow etc.) and Work Breakdown Structure (WBS) analysis can be used to determine the precise actions and the event times of the project with the complete satisfaction of stakeholders (Hellenic Army - Logistics Companies).

Warehouses are one of the most important components in the supply chain management. The main 
roles that they play in the operational planning of the military logistics management includes the material flow along the supply chain to accommodate variability caused by factors such as batching transportation, and the value-added-processing with activities such as kitting, packaging, labeling, and product customization (clarified as a material, spare part, autonomous material etc.).

In this paper, the optimization proposal for the strategic management process of the utilization operation of the Hellenic Army Empty Warehouses is based on the given advantageous geographical position of the Units. In this context and taking into consideration the amount of the old existing warehouses it is imperative to extend this study in two axes: The first one to remain only in the exploitation of some storage facilities and the second to seek their expansion in permanent installations or movable storage rooms and warehouses by deciding which is the best effectiveness solution. This future work concerns facilities of the same military camp and the two axes must be determined both simultaneously, with the development of one or more feasibility studies.

The development of these feasibility studies should be focused in the field of the strategic location of the facilities by minimizing the total expected opportunity loss of the change in the operational use of the warehouses and in the field of financial management in order to exploit the existing financial resources and try to approach the new forms of investment presented in this optimization proposal (in the functional level). For the implementation of the project it must be considered multiple criteria such as the cost and the risk in the uncertain business environment that will lead us achieve the Fully Employment of the warehouses of the Hellenic Military.

\section{References}

1. G. Johnson, K. Scholes, R. Whittington, Fundamentals of Strategy, Pearson Education, 2009

2. M. Hitt, R. Ireland, R. Hoskisson, Strategic Management: Competitiveness \& Globalization: Concepts and Cases, 11th ed, Cengage Learning, 2015

3. M. Porter. The Five Competitive Forces that Shape Strategy, Harvard Bus. Rev. 2008, pp.86-104

4. M. Porter, Competitive Advantage, The Free Press, NY, 1985

5. B. Donath, J. Mazen, C. Dubin, P. Patterson, The IOMA handbook of logistics and inventory management, Inst. Mngmt and Ad, John Wiley \& Sons, Inc., NY, 2002.

6. D. Simchi-Levi, B.J. Chen Xin, The Logic of Logistics: Theory, Algorithms and Applications for Logistics Management, Springer, 2014

7. B.A. Wayland, Security for Business Professionals: How to plan, implement, and manage your company's security program, ButterworthHeinemann, pp 52-60, 100-106, 2014

8. T.A. Shimp, Advertising, Promotion, and Other Aspects of Integrated Marketing Communication London: South Western-Cengage Business, 2010

9. Th. Zikos, D. Zaires, N.V.Karadimas, Automated Procedure for Utilization - Operation of Hellenic Army Empty Warehouses, (to be published). 